\title{
Plasma properties of superstorms at geosynchronous orbit: How different are they?
}

\author{
M. W. Liemohn, ${ }^{1}$ J.-C. Zhang, ${ }^{2}$ M. F. Thomsen, ${ }^{3}$ J. E. Borovsky, ${ }^{3}$ J. U. Kozyra, ${ }^{1}$ \\ and R. Ilie ${ }^{1}$ \\ Received 20 August 2007; revised 1 October 2007; accepted 16 October 2007; published 25 January 2008.
}

[1] Plasma measurements at geosynchronous orbit are examined via superposed epoch analysis for various storm categories to assess whether superstorms have an unusually altered source population for the storm-time ring current. It is found that certain characteristics of this near-Earth plasma distribution during superstorms are similar to those of moderate or intense storms, or extensions of the trends seen in these lesser storms. These similarities include the dawn sector development of cold, dense plasma. However, other characteristics are unique to superstorms, such as the existence of cold, dense plasma at dusk and midnight. It is concluded that the ring current source during superstorms is a combination of the usual storm-time characteristics as well as an unusually altered component. Citation: Liemohn, M. W., J.-C. Zhang, M. F. Thomsen, J. E. Borovsky, J. U. Kozyra, and R. Ilie (2008), Plasma properties of superstorms at geosynchronous orbit: How different are they?, Geophys. Res. Lett., 35, L06S06, doi:10.1029/2007GL031717.

\section{Introduction}

[2] Superstorms, the largest 2\% magnetospheric disturbances with a minimum Dst index below -250 nT [Bell et al., 1997], have received much attention lately. This is in part because the last solar cycle resulted in at least 10 such storms, a rather large percentage compared to the Bell et al. [1997] historical average. Several special sections of journals have been devoted to studies on the superstorms of July 2000 and October 2003 [see, e.g., Jordanova et al., 2001; Gopalswamy et al., 2005].

[3] Mac-Mahon and Gonzalez [1997] made the finding that, during superstorms, an unusually high amount of energy goes into the ring current relative to other energy sinks (e.g., ionospheric Joule heating). This raises the question of whether the magnetosphere, and in particular the drivers of the ring current, are preferentially different during superstorms.

[4] There are two main driver terms for the storm-time ring current, the near-Earth plasma sheet and the large-scale convection electric field [Kozyra and Liemohn, 2003]. Several studies have examined these parameters for specific superstorms. Regarding the plasma sheet source population, several studies have commented on the existence of the superdense plasma sheet and its relationship to intense

\footnotetext{
${ }^{1}$ Atmospheric, Oceanic, and Space Sciences Department, University of Michigan, Ann Arbor, Michigan, USA.

${ }^{2}$ Department of Physics and Astronomy, Rice University, Houston, Texas, USA.

${ }^{3}$ Los Alamos National Laboratory, Los Alamos, New Mexico, USA.
}

Copyright 2008 by the American Geophysical Union. 0094-8276/08/2007GL031717 magnetic storms [e.g., Borovsky et al., 1997; Kozyra et al., 1998; Thomsen et al., 2003]. For instance, Oieroset et al. [2005] showed that the entire plasma sheet became cold and dense during an extended northward IMF interval, a result of reconnection poleward of the cusp [Li et al., 2005]. Others have also noted the strong relationship between superdense plasma sheets and preceding northward IMF intervals [Thomsen et al., 2003; Lavraud et al., 2006a, 2006b].

[5] Composition of the ring current source population is also a factor in storm strength. For the 29-31 October 2003 superstorms, Nosé et al. [2005] found that $\mathrm{O}^{+}$dominated the plasma sheet energy density in the near-Earth magnetotail. Others have also found a clear link between storm intensity and an increased $\mathrm{O}^{+}$density in the near-Earth plasma sheet and ring current [e.g., Young et al., 1982; Daglis et al., 1993; Pulkkinen et al., 2001; Fu et al., 2002].

[6] The development of the large-scale electric field in the magnetosphere during superstorms has also been investigated recently. Hairston et al. [2003, 2005] noted the saturation of the cross polar cap potential during superstorms, as seen by the DMSP spacecraft. They note that there seems to be a saturation limit of about $260 \mathrm{kV}$ to this parameter. Liemohn et al. [2002] and Ebihara et al. [2005] conducted detailed modeling studies of particular superstorms, concluding that the development of the ring current during these events was consistent with the observed saturation of the cross polar cap potential. The region 2 field-aligned current pattern, and the resulting inner magnetospheric convection pattern, can be very complicated during intense magnetic storms [e.g., Liemohn and Brandt, 2005; Ebihara et al., 2005]. Similarly, Nishimura et al. [2007] analyzed Akebono electric field data during the November 1989 superstorm, finding the largest E-fields (up to $6 \mathrm{mV} / \mathrm{m}$ ) deep within the inner magnetosphere, like the CRRES observations of Wygant et al. [1998] during the March 1991 superstorm.

[7] In this study, a systematic examination of the ring current source population is considered, in order to determine if it is unusually altered during superstorms relative to more normal magnetic storm events. In particular, the methodology of superposed epoch analysis of geosynchronous orbit plasma data will be used. Specifically, storms occurring during the last solar maximum are categorized into moderate, intense, and superstorms, and the resulting average plasma properties at geosynchronous orbit are compared and analyzed.

\section{Methodology}

[8] Superposed epoch analysis (SEA) is a method of combining data from similar but distinct events by defining 
an appropriate and identifiable reference time within each event to serve as a fiducial mark. Timelines for each event are set so that $\mathrm{t}=0$ at this reference time, allowing for the data to be compared, averaged, and analyzed. The timings of features in the SEA data are then relative to the common feature used to set the reference time for each event.

[9] Here, SEA is used on data from the magnetospheric plasma analyzer (MPA) instruments on the geosynchronously orbiting satellites operated by the Los Alamos National Laboratory (LANL). The MPA instruments are electrostatic analyzers that measure ion and electron fluxes from $0.1 \mathrm{eV}$ up to $45 \mathrm{keV}$ [Bame et al., 1993]. This technique has been used in many studies of this data set [e.g., Denton et al., 2005, 2006; Lavraud et al., 2005; Zhang et al., 2006]. This work expands on the study of Zhang et al. [2006], using the same time interval definition of solar maximum as they did for the baseline moderate and intense storms, but adding a new category of superstorms to the comparison.

[10] The LANL MPA data set is well suited for this type of analysis. At times during the last solar cycle, up to 7 LANL spacecraft were operating at geosynchronous orbit, providing good local time coverage for many of the events. By superposing the data from all similarly-sized storm events, it is possible to construct a view of the local time vs. epoch time plasma parameter development before, during, and after the storms for each event class.

[11] The details of the event selection and data processing are given by Zhang et al. [2006]. The hot ion fluxes (100 eV to $45 \mathrm{keV}$ ) are used in the moments calculation, a range that contains the bulk of the near-Earth plasma sheet density. An assumption in the moment calculation is that all ions are protons. This is not strictly true, and certainly may not be the case during large magnetic disturbances, but given the lack of specific composition information for all of the storm events, this assumption is applied. Note that Young et al. [1982] found that $\left[\mathrm{O}^{+}\right] /\left[\mathrm{H}^{+}\right]$rarely exceeds unity for energies below $17 \mathrm{keV}$ at geosynchronous orbit. For typical solar maximum conditions $(\mathrm{F} 10.7=200)$, the Young et al. [1982] formulas require a $\mathrm{Kp}$ value of 6.6 for the $\mathrm{O}^{+}$density to equal that of $\mathrm{H}^{+}$(similar to the statistics of Pulkkinen et al. [2001] and Fu et al. [2002]). Enhancements in MPAderived densities during major magnetic storms may well be underestimated in this study if the ionospheric contribution to the plasma sheet is strong. If the plasma were completely $\mathrm{O}^{+}$instead of $\mathrm{H}^{+}$, the density would be four times higher than that computed assuming $100 \% \mathrm{H}^{+}$content [see, e.g., Liemohn et al., 1999]. The temperature would be unaffected, because MPA measures E/q.

[12] A limitation placed on data selection is that the spacecraft should be in the plasma sheet. In order to exclude times when the spacecraft are in the magnetosheath, lowlatitude boundary layer, and magnetotail lobes, several criteria are applied, namely that $0.3 \mathrm{~cm}^{-3}<\mathrm{N}_{\mathrm{HP}}<6 \mathrm{~cm}^{-3}$ and $\mathrm{T}_{\text {HP,perp }}>2 \mathrm{keV}$ [e.g., Korth et al., 1999].

[13] Event selection is limited to the last solar maximum period. Specifically, the years 1999-2002 are used to define solar maximum for the moderate and intense magnetic storms. For the superstorms, the interval is extended from 1999-2004, in order to increase the data statistics. The three storm categories are defined based on the parameter Dst*, which is the storm-time magnetic disturbance index
Dst corrected for solar wind dynamic pressure $\mathrm{P}_{\mathrm{dyn}}$ [Gonzalez et al., 1994],

$$
\mathrm{Dst}^{*}=\mathrm{Dst}-7.26 \mathrm{P}_{\mathrm{dyn}}^{1 / 2}+11 \mathrm{nT}
$$

A correction for the contribution from the induced currents inside the Earth is not included in order to keep this definition consistent with others who have defined a Dst* threshold for storm magnitudes. The storm magnitude categories used here are as follows [Gonzalez et al., 1994; Bell et al., 1997]:

$$
\begin{gathered}
\text { Superstorms : Dst } t_{\mathrm{min}}^{*} \leq-250 \mathrm{nT} \\
\text { Intense storms : }-250 \mathrm{nT}<D s t_{\mathrm{min}}^{*} \leq-100 \mathrm{nT} \\
\text { Moderate storms : }-100 \mathrm{nT}<D s t_{\mathrm{min}}^{*} \leq-50 \mathrm{nT}
\end{gathered}
$$

where the "min" subscript indicates the minimum Dst* value during that particular storm interval. This yields 63 moderate storms, 34 intense storms, and 10 superstorms for the superposed epoch analysis.

[14] The reference time chosen for this study is the same as that used by Zhang et al. [2006], i.e., the time of $D s t^{*}{ }_{\text {min }}$. This is a useful choice, because it aligns the data near the peak of the storm interval, when the ring current is building to its maximum intensity, and when the drivers of the ring current should be at their peak values as well.

\section{Results}

[15] Figure 1 shows the superposed epoch results for the moderate, intense, and superstorm classes, presenting local time-epoch time (LT-ET) distributions of the hot-ion density and temperature, compiled from the MPA moments, and the superposed Dst* time series for each storm category. The first two columns of Figure 1 are essentially the same as that from Zhang et al. [2006]. The color scales are linear and given to the right of each row. Purple (black) indicates values beyond the top (bottom) of the color scale. White indicates a lack of data for that grid cell in the LT-ET distribution.

[16] Some differences are evident between superstorms and the other two categories. First, the density is much higher during superstorms, showing several peaks in LT and ET. There appears to be a dawn and a dusk density peak at roughly 9-12 hours prior to the Dst* minimum as well as an enhancement at all LTs coincident with Dst* ${ }_{\text {min }}$. Note that these early peaks are not because of a prior storm event corrupting the superposition average. Most of the superstorms are isolated events, and these early peaks are consistent features in the individual-storm MPA data plots. The midnight peaks are missing from the moderate and intense storm averages, and they have only a slight density increase near dusk. The temperature distribution shows a tendency toward lower average values with increasing storm size. In addition, there is a dramatic reduction in the observed temperature across all LTs right before Dst* ${ }_{\text {min }}$ in the superstorm averages. When examining the individual storm data (not shown), it is seen that the density peaks are consistent features of most of the superstorms, and the 

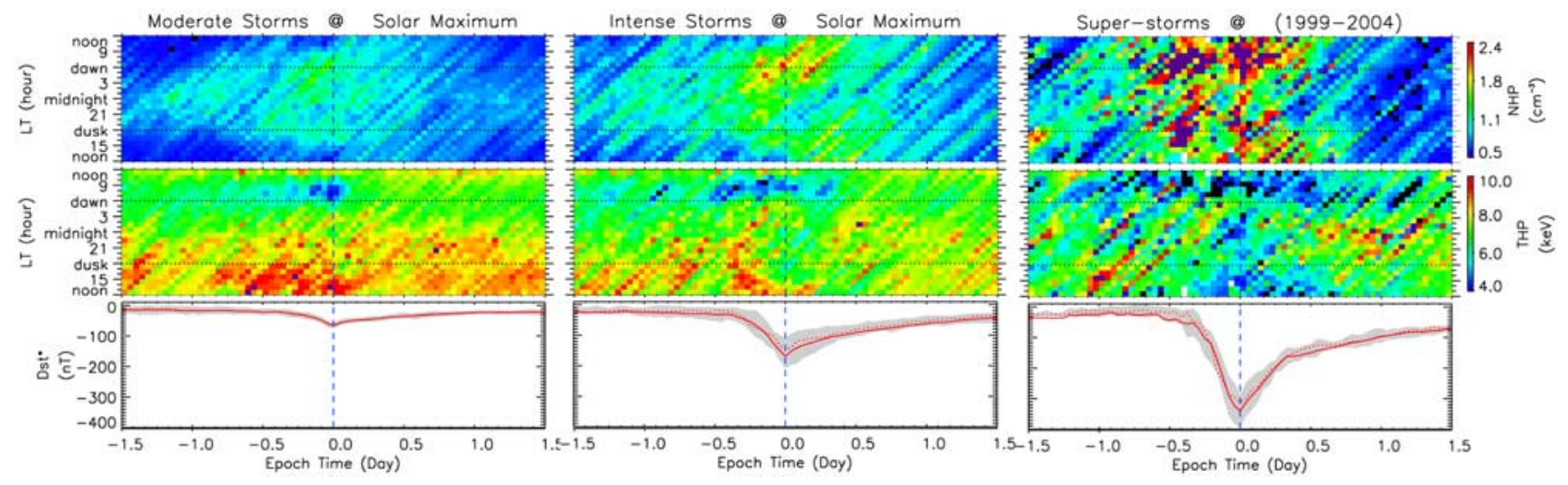

Figure 1. Superposed epoch data from the MPA instruments for different categories of storms at solar maximum, by column: (left) moderate, $-100 \mathrm{nT}<D s t^{*}{ }_{\min } \leq-50 \mathrm{nT}$; (middle) intense, $-250 \mathrm{nT}<D s t^{*}{ }_{\min } \leq-100 \mathrm{nT}$; and (right) superstorms, $-250 \mathrm{nT} \leq D s t^{*}{ }_{\text {min. }}$. (top) Hot ion density (in $\mathrm{cm}^{-3}$ ), (middle) hot ion temperature (in $\mathrm{keV}$ ), and (bottom) Dst* (in nT). The shaded region around the red line in Figure 1 (bottom) shows the first and third quartiles of the Dst* range from the events within that category.

averages are not being skewed by one or two extreme events.

[17] To more quantitatively investigate these results, Figures 2 and 3 present line plots of the average density and temperature for each storm category at specific ETs (Figure 2) and LTs (Figure 3). Figure 2 (LT profiles at specific ETs: $-6 \mathrm{~h},-4 \mathrm{~h}$, and $-2 \mathrm{~h}$ ) reveals the magnitude of the superstorm density peaks and temperature troughs relative to those of the other storm categories. Figures 2a, $2 \mathrm{~b}$, and $2 \mathrm{c}$ show that all 3 storm classes develop a density peak just past dawn. It also clearly illustrates the development of a second peak at $\mathrm{t}=-2 \mathrm{~h}$ near dusk, a feature not seen in the other 2 storm categories. Figures $2 \mathrm{~d}, 2 \mathrm{e}$, and $2 \mathrm{f}$ show that all 3 storm classes develop a temperature minimum just past dawn. The minimum value is just slightly lower for superstorms, but within $1 \mathrm{keV}$ of the moderate storm minimum value at all 3 ETs presented. The unique feature in the superstorm temperature profiles is the midnight/dusk temperature minimum. The entire superstorm temperature profile from midnight westward is depressed by $1-3 \mathrm{keV}$ relative to the other 2 storm categories, and the $\mathrm{t}=-2 \mathrm{~h}$ midnight minimum is nearly as deep as the postdawn minimum. The pre-dawn temperature maximum closely matches the temperature profiles of the other 2 storm categories in this sector.

[18] Figure 3 (ET series at specific LTs: 18, 00, and 04) further demonstrates the relative differences between the density and temperature extrema between the 3 storm categories. At dusk $(\mathrm{LT}=18)$, there is a substantial density peak near $\mathrm{t}=0$, accompanied by a significant temperature
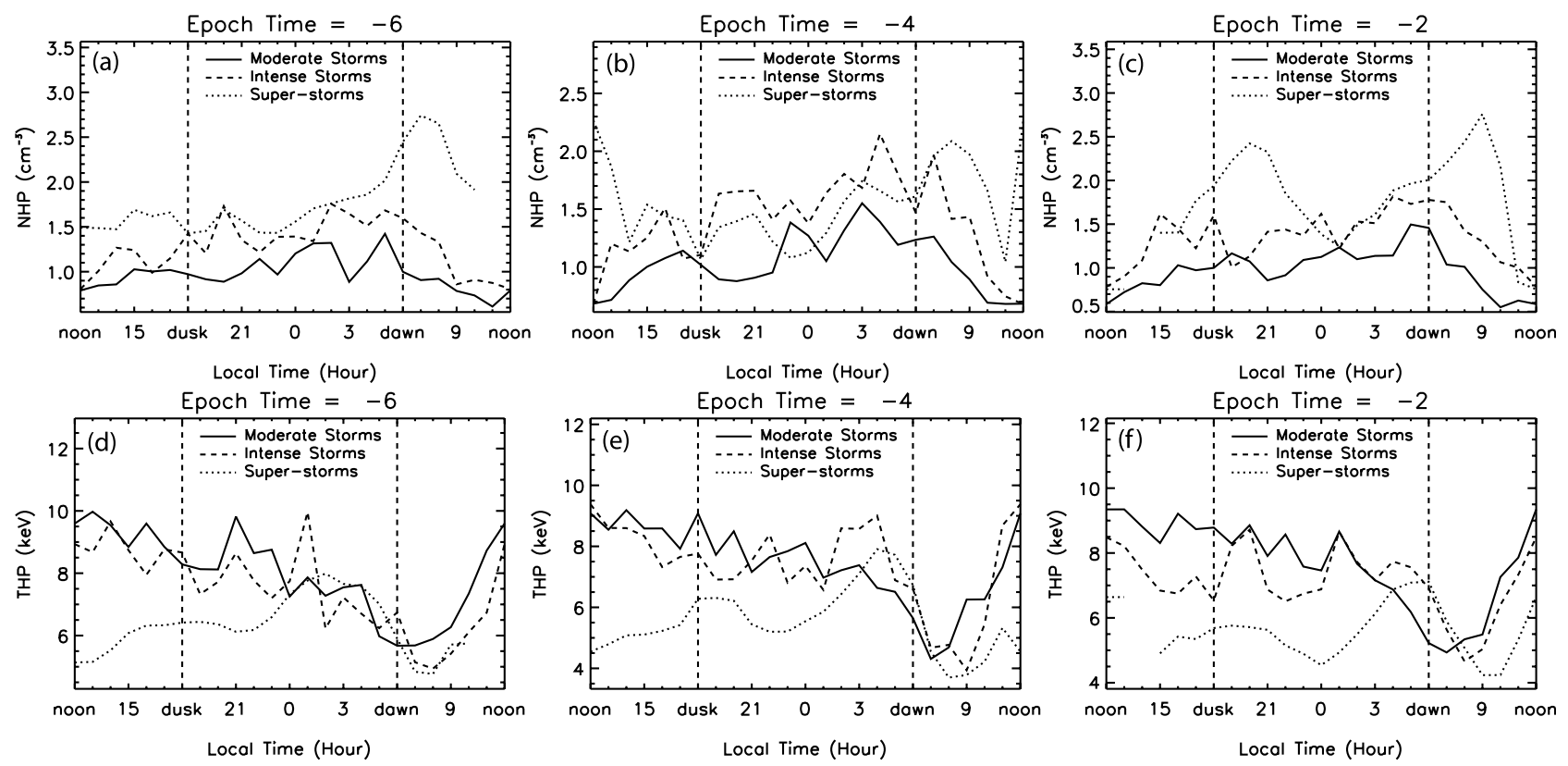

Figure 2. LT profiles extracted from the results in Figure 1 at ET $=($ left $)-6 \mathrm{~h}$, (middle) $-4 \mathrm{~h}$, and (right) $-2 \mathrm{~h}$. Each storm category has a different line style (moderate, solid; intense, dashed; super, dotted). (top) Hot ion density and (bottom) hot ion temperature. The two vertical dashed lines denote dusk and dawn. 

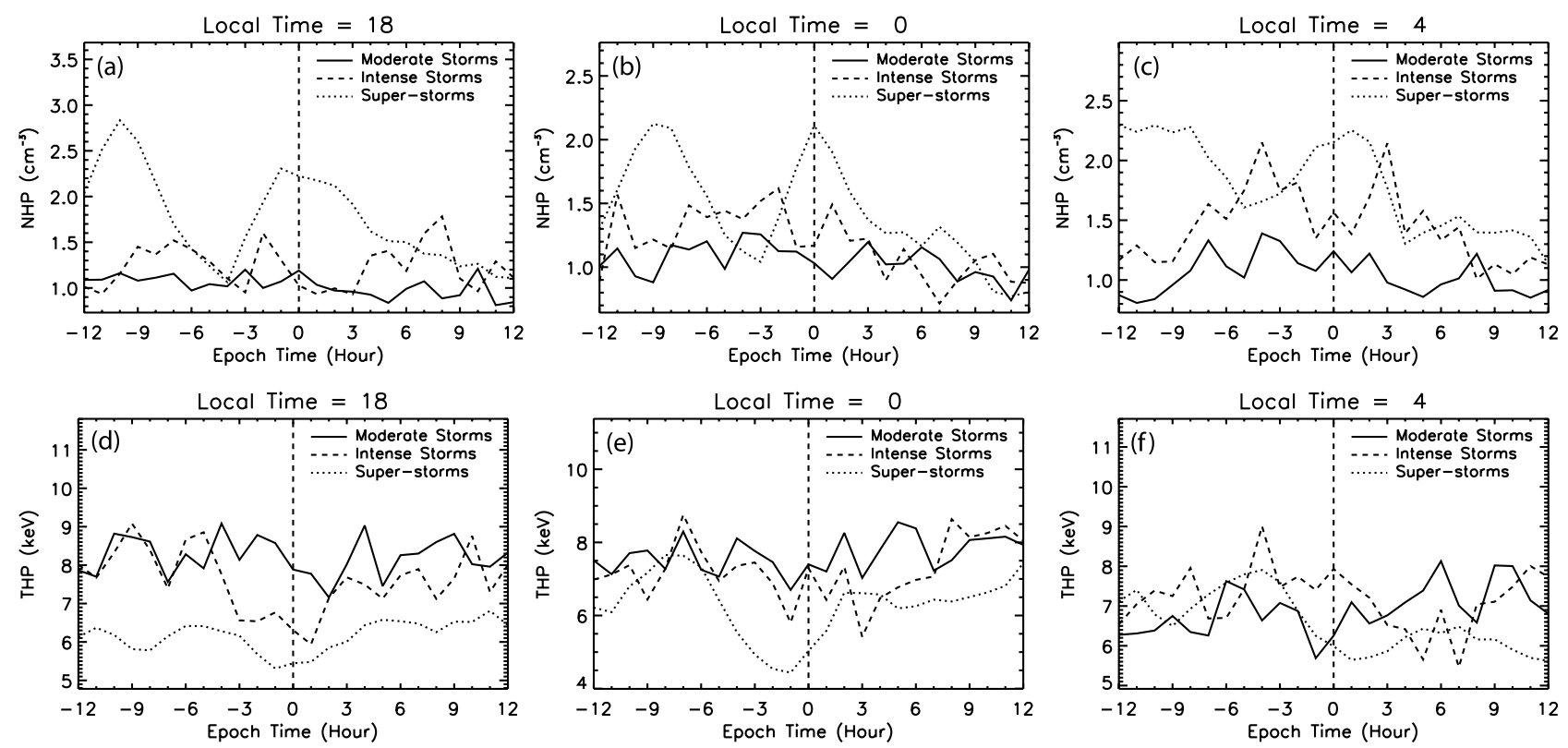

Figure 3. ET series extracted from the results in Figure 1 at $\mathrm{LT}=$ (left) 18 , (middle) 00, and (right) 04. The format is the same as in Figure 2. The vertical dashed line shows the zero epoch time.

reduction. The temperature profile, however, appears to be a continuation of a trend seen between the moderate and intense storms; the intense storm averages also show a temperature dip just before Dst* ${ }_{\text {min }}$. At midnight (LT $=$ 00 ), again there is a density spike and temperature drop near $\mathrm{t}=0$. Neither of these trends is seen in the other 2 storm categories. In the pre-dawn region $(\mathrm{LT}=04)$, the density systematically increases with storm size and the temperature is relatively low for all 3 storm categories.

[19] Let us make a comment on the significance of these results. In general, the standard deviations $(\sigma)$ for density are less than $0.5 \mathrm{~cm}^{-3}$ for the moderate and intense storms, and vary between 0.5 to $1.8 \mathrm{~cm}^{-3}$ for the superstorm values. For temperature, moderate and intense storms have $\sigma<$ $0.5 \mathrm{keV}$, while superstorms have $0.5<\sigma<2 \mathrm{keV}$. Usually, $\sigma$ is larger for higher $\mathrm{n}$ or $\mathrm{T}$. We find that the features that we highlight in this paper are significant.

\section{Discussion and Conclusions}

[20] The data presented above shows clear similarities and differences between superstorms and other storm categories in these superposed geosynchronous orbit plasma data. Some of the differences follow a systematic trend with increasing storm size, while other differences are unique to the superstorm category. There are several conclusions that can be drawn from these results regarding geosynchronous plasma characteristics for storms at solar maximum.

[21] Regarding the similarities of superstorms with other storm classes, it is seen that there is: (1) a systematic temperature drop in the post-dawn sector, reaching 4$6 \mathrm{keV}$ regardless of storm size; (2) a systematic density enhancement in the post-dawn sector, which increases with storm size; and (3) a systematic temperature drop near dusk, which deepens with storm size.

[22] Regarding the unique differences of superstorms with other storm classes, it is seen that there is: (4) a rapid and large density increase across the nightside at the time of the storm peak; (5) a large density increase near dusk just before the storm peak; (6) a density peak $\sim 9$ hours before the storm peak; and (7) a deep temperature minimum near midnight just before the storm peak.

[23] These findings lead to the conclusion that, within the source of the ring current as seen by the MPA instruments on the LANL-operated geosynchronous orbit satellites, there are some aspects of superstorms that are simply systematic extensions of features seen in moderate and intense storms at solar maximum. However, there are other aspects that are unique to the superstorm category. In particular, all categories of storms exhibit the development of a cold and dense plasma sheet in the dawn/post-dawn sector, but a defining characteristic of a superstorm is the existence of cold and dense near-Earth plasma sheet material at midnight and dusk. This additional cold, dense source population for the ring current allows for the development of a stronger ring current [e.g., Ebihara and Ejiri, 2000; Garner, 2003; Lemon et al., 2004; Lavraud and Jordanova, 2007], and thus a deeper Dst* depression. The present study does not distinguish whether this additional cold, dense plasma sheet is of solar wind origin [e.g., Li et al., 2005; Lavraud et al., 2006a] or of ionospheric origin [e.g., Nosé et al., 2005], just that it systematically exists during the main phase of superstorms. Note, however, that Lavraud et al. [2005] found the cold, dense plasma sheet to be $\mathrm{H}^{+}$ dominated, even at solar maximum.

[24] It is concluded that the ring current source during superstorms is a combination of the usual storm-time characteristics as well as an unusually altered component. It is believed that these superstorm-specific characteristics are a primary cause of the extra-large ring current during such events, because they are different in a way that favors the development of a strong ring current. This result provides an explanation for the conclusion of Mac-Mahon and Gonzalez [1997], who found that an unusually large 
fraction of energy goes into the ring current during superstorms. It is found here that the ring current is preferentially intensified during superstorms.

[25] Acknowledgments. The authors would like to thank NASA and NSF for supporting this research (specifically grants NNG05GE02G, NNG05GM48G, NNG05GJ89G, and ATM-0203163), and also LANL IGPP for additional support of the graduate student involvement in this study. Work at Los Alamos was conducted under the auspices of the U. S. Department of Energy with partial support from the NASA Heliophysics Guest Investigator program. We would also like to thank the Kyoto World Data Center for access to the Dst index, and NSSDC for access to the ACE solar wind data (for calculating Dst*).

\section{References}

Bame, S. J., et al. (1993), Magnetospheric plasma analyzer for spacecraft with constrained resources, Rev. Sci. Instrum., 64, 1026.

Bell, J. T., M. S. Gussenhoven, and E. G. Mullen (1997), Super storms, J. Geophys. Res., 102, 14,189.

Borovsky, J. E., M. F. Thomsen, and D. J. McComas (1997), The superdense plasma sheet: Plasmaspheric origin, solar wind origin, or ionospheric origin?, J. Geophys. Res., 102, 22,089.

Daglis, I. A., E. T. Sarris, and B. Wilken (1993), AMPTE/CCE observations of the ion population at geosynchronous altitudes, Ann. Geophys., 11,685 .

Denton, M. H., M. F. Thomsen, H. Korth, S. Lynch, J. C. Zhang, and M. W. Liemohn (2005), Bulk plasma properties at geosynchronous orbit, J. Geophys. Res., 110, A07223, doi:10.1029/2004JA010861.

Denton, M. H., J. E. Borovsky, R. M. Skoug, M. F. Thomsen, B. Lavraud, M. G. Henderson, R. L. McPherron, J. C. Zhang, and M. W. Liemohn (2006), Geomagnetic storms driven by ICME- and CIR-dominated solar wind, J. Geophys. Res., 111, A07S07, doi:10.1029/2005JA011436.

Ebihara, Y., and M. Ejiri (2000), Simulation study on fundamental properties of the storm-time ring current, J. Geophys. Res., 105, 15,843.

Ebihara, Y., M.-C. Fok, S. Sazykin, M. F. Thomsen, M. R. Hairston, D. S. Evans, F. J. Rich, and M. Ejiri (2005), Ring current and the magnetosphere-ionosphere coupling during the superstorm of 20 November 2003, J. Geophys. Res., 110, A09S22, doi:10.1029/2004JA010924.

Fu, S. Y., Q. G. Zong, T. A. Fritz, Z. Y. Pu, and B. Wilken (2002), Composition signatures in ion injections and its dependence on geomagnetic conditions, J. Geophys. Res., 107(A10), 1299, doi:10.1029/2001JA002006.

Garner, T. W. (2003), Numerical experiments on the inner magnetospheric electric field, J. Geophys. Res., 108(A10), 1373, doi:10.1029/ 2003JA010039.

Gonzalez, W. D., J. A. Joselyn, Y. Kamide, H. W. Kroehl, G. Rostoker, B. T. Tsurutani, and V. M. Vasyliunas (1994), What is a geomagnetic storm?, J. Geophys. Res., 99, 5771.

Gopalswamy, N., L. Barbieri, E. W. Cliver, G. Lu, S. P. Plunkett, and R. M. Skoug (2005), Introduction to violent Sun-Earth connection events of October-November 2003, J. Geophys. Res., 110, A09S00, doi:10.1029/ 2005JA011268.

Hairston, M. R., T. W. Hill, and R. A. Heelis (2003), Observed saturation of the ionospheric polar cap potential during the 31 March 2001 storm, Geophys. Res. Lett., 30(6), 1325, doi:10.1029/2002GL015894.

Hairston, M. R., K. A. Drake, and R. Skoug (2005), Saturation of the ionospheric polar cap potential during the October-November 2003 superstorms, J. Geophys. Res., 110, A09S26, doi:10.1029/2004JA010864.

Jordanova, V. K., et al. (2001), Ring current dynamics during the 1318 July 2000 storm period, Sol. Phys., 204, 361.

Korth, H., M. F. Thomsen, J. E. Borovsky, and D. J. McComas (1999), Plasma sheet access to geosynchronous orbit, J. Geophys. Res., 104, 25,047 .

Kozyra, J. U., and M. W. Liemohn (2003), Ring current energy input and decay, Space Sci. Rev., 109, 105.

Kozyra, J. U., V. K. Jordanova, J. E. Borovsky, M. F. Thomsen, D. J. Knipp, D. S. Evans, D. J. McComas, and T. E. Cayton (1998), Effects of a high-density plasma sheet on ring current development during the November 2-6, 1993 magnetic storm, J. Geophys. Res., 103, $26,285$.

Lavraud, B., and V. K. Jordanova (2007), Modeling the effects of colddense and hot-tenuous plasma sheet on proton ring current energy and peak location, Geophys. Res. Lett., 34, L02102, doi:10.1029/ 2006GL027566.

Lavraud, B., M. H. Denton, M. F. Thomsen, J. E. Borovsky, and R. H. W. Friedel (2005), Superposed epoch analysis of dense plasma access to geosynchronous orbit, Ann. Geophys., 23, 2519.
Lavraud, B., M. F. Thomsen, B. Lefebvre, S. J. Schwartz, K. Seki, T. D. Phan, Y. L. Wang, A. Fazakerley, H. Rème, and A. Balogh (2006a), Evidence for newly closed magnetosheath field lines at the dayside magnetopause under northward IMF, J. Geophys. Res., 111, A05211, doi:10.1029/2005JA011266.

Lavraud, B., M. F. Thomsen, J. E. Borovsky, M. H. Denton, and T. I. Pulkkinen (2006b), Magnetosphere preconditioning under northward IMF: Evidence from the study of coronal mass ejection and corotating interaction region geoeffectiveness, J. Geophys. Res., 111, A09208, doi:10.1029/2005JA011566.

Lemon, C., R. A. Wolf, T. W. Hill, S. Sazykin, R. W. Spiro, F. R. Toffoletto, J. Birn, and M. Hesse (2004), Magnetic storm ring current injection modeled with the Rice Convection Model and a self-consistent magnetic field, Geophys. Res. Lett., 31, L21801, doi:10.1029/2004GL020914.

Li, W., J. Raeder, J. Dorelli, M. Øieroset, and T. D. Phan (2005), Plasma sheet formation during long period of northward IMF, Geophys. Res. Lett., 32, L12S08, doi:10.1029/2004GL021524.

Liemohn, M. W., and P. C. Brandt (2005), Small-scale structure in the stormtime ring current, in Inner Magnetosphere Interactions: New Perspectives from Imaging, Geophys. Monogr. Ser., vol. 159, edited by J. L. Burch, M. Schulz, and H. Spence, p. 167, AGU, Washington, D. C.

Liemohn, M. W., J. U. Kozyra, V. K. Jordanova, G. V. Khazanov, M. F. Thomsen, and T. E. Cayton (1999), Analysis of early phase ring current recovery mechanisms during geomagnetic storms, Geophys. Res. Lett., 25, 2845.

Liemohn, M. W., J. U. Kozyra, M. R. Hairston, D. R. Weimer, G. Lu, A. J. Ridley, T. H. Zurbuchen, and R. M. Skoug (2002), Consequences of a saturated convection electric field on the ring current, Geophys. Res. Lett., 29(9), 1348, doi:10.1029/2001GL014270.

Mac-Mahon, R. M., and W. D. Gonzalez (1997), Energetics during the main phase of geomagnetic superstorms, J. Geophys. Res., 102, 14,199.

Nishimura, Y., A. Shinbori, T. Ono, M. Iizima, and A. Kumamoto (2007), Evolution of ring current and radiation belt particles under the influence of storm-time electric fields, J. Geophys. Res., 112, A06241, doi:10.1029/ 2006JA012177.

Nosé, M., S. Taguchi, K. Hosokawa, S. P. Christon, R. W. McEntire, T. E. Moore, and M. R. Collier (2005), Overwhelming $\mathrm{O}^{+}$contribution to the plasma sheet energy density during the October 2003 superstorm: Geotail/EPIC and IMAGE/LENA observations, J. Geophys. Res., 110, A09S24, doi:10.1029/2004JA010930.

Øieroset, M., J. Raeder, T. D. Phan, S. Wing, J. P. McFadden, W. Li, M. Fujimoto, H. Rème, and A. Balogh (2005), Global cooling and densification of the plasma sheet during an extended period of purely northward IMF on October 22-24, 2003, Geophys. Res. Lett., 32, L12S07, doi:10.1029/2004GL021523.

Pulkkinen, T. I., N. Y. Ganushkina, D. N. Baker, N. E. Turner, J. F. Fennell, J. Roeder, T. A. Fritz, M. Grande, B. Kellett, and G. Kettmann (2001), Ring current ion composition during solar minimum and rising solar activity: Polar/CAMMICE/MICS results, J. Geophys. Res., 106, 19,131.

Thomsen, M. F., J. E. Borovsky, R. M. Skoug, and C. W. Smith (2003), Delivery of cold, dense plasma sheet material into the near-Earth region, J. Geophys. Res., 108(A4), 1151, doi:10.1029/2002JA009544.

Wygant, J., D. Rowland, H. J. Singer, M. Temerin, F. Mozer, and M. K. Hudson (1998), Experimental evidence on the role of the large spatial scale electric field in creating the ring current, J. Geophys. Res., 103, $29,527$.

Young, D. T., H. Balsiger, and J. Geiss (1982), Correlations of magnetospheric ion composition with geomagnetic and solar activity, J. Geophys. Res., 87, 9077.

Zhang, J., M. W. Liemohn, M. F. Thomsen, J. U. Kozyra, M. H. Denton, and J. E. Borovsky (2006), A statistical comparison of hot-ion properties at geosynchronous orbit during intense and moderate geomagnetic storms at solar maximum and minimum, J. Geophys. Res., 111, A07206, doi:10.1029/2005JA011559.

J. E. Borovsky and M. F. Thomsen, Los Alamos National Laboratory, Mail Stop D466, Los Alamos, NM 87545, USA.

R. Ilie, J. U. Kozyra, and M. W. Liemohn, Atmospheric, Oceanic, and Space Sciences Department, University of Michigan, 2455 Hayward Street, Ann Arbor, MI 48109-2143, USA. (liemohn@umich.edu)

J.-C. Zhang, Department of Physics and Astronomy, Rice University, 6100 Main Street, Houston, TX 77005, USA. 